\title{
O desafio da mobilização institucional na formação docente
}

\author{
The challenge of institutional's mobilisation on teacher's formation \\ El desafío de la movilización institucional en la formación docente
}

\author{
PATRÍCIA MEYER* \\ CINTHIA BITENCOURT SPRICIGO** \\ ELISANGELA FERRETTI MANFFRA*** \\ DILMEIRE SANT'ANNA RAMOS VOSGERAU ${ }^{* * * *}$
}

\begin{abstract}
$\diamond$
RESUMO

A promoção do desenvolvimento profissional de professores é um desafio para as instituições de ensino superior que buscam a excelência na qualidade de ensino. Dentre os entraves está a dificuldade em equilibrar as necessidades individuais e institucionais, assim como envolver não apenas os professores, mas também colaboradores, gestores e estudantes. Este estudo de caso tem por objetivo examinar o desafio da mobilização institucional na formação docente a partir da atuação do setor responsável por essas estratégias no âmbito de uma universidade comunitária confessional, adotando como referencial teórico para análise Zabalza (2004), Saroyan e Amundsen (2004), Cunha (2010) e Veiga et al. (2012). Estuda-se como o processo de criação e consolidação do Centro de Ensino e Aprendizagem (2014-2016) ocorreu, contemplando o contexto de origem, a articulação administrativa e as características do programa de formação instituído. Destacam-se, dentre as medidas tomadas para engajar e legitimar as ações, a adoção de diversas frentes de atuação simultâneas, o reconhecimento às boas práticas docentes e o incentivo ao compartilhamento de experiências. Palavras-chave: Ensino superior. Desenvolvimento profissional. Formação docente. Professor universitário.
\end{abstract}

\begin{abstract}
The furtherance of teacher's professional development is a challenge for higher education institutes which aim for teaching excellence. Among the hindrances, there is the difficulty of balance between individual and institutional's needs as well involving not only professors but also collaborators, managers and students. Therefore, this case study discusses the challenge of institutional's mobilisation on teacher's formation. The scope evaluated is the responsible department for teacher's formation strategies on a private higher education institution. The chosen department is the Centro de Ensino e Aprendizagem (2014-2016) where happened the creation and consolidation process of this strategies. Contemplated in this case study are: original context, administrative articulation and characteristics of the established formation program. Among the measures taken to involve and to legitimate actions, it is possible to highlight the take-up of a diverse simultaneous acting front, the recognition of good teaching practices and the incentive to experience sharing.

Keywords: Higher education. Professional development. Faculty development. University professor.

\section{RESUMEN}

La promoción del desarrollo profesional de profesores es un desafío para las instituciones de Educación Superior que buscan la excelencia en calidad de enseñanza. De entre los obstáculos está la dificultad en equilibrar las necesidades individuales e institucionales, así como involucrar no sólo los profesores, sino también colaboradores, administradores y estudiantes. Este estudio de caso tiene por objetivo examinar el desafío de la movilización institucional en la formación docente a partir de la actuación del sector responsable por esas estrategias en el ámbito de una universidad comunitaria confesional, adoptándose como referencial teórico para análisis Zabalza (2004), Saroyan y Amundsen (2004), Cunha (2010) y Veiga et al. (2012). Se estudia como ocurrió el proceso de creación y consolidación del Centro de Enseñanza y Aprendizaje (2014-2016) contemplándose el contexto de origen, la articulación administrativa y las características del programa de formación instituido. De todas las acciones tomadas para comprometer y legitimar los actos se señalan la adopción de distintos frentes de actuaciones simultáneas, el reconocimiento a las buenas prácticas docentes y el incentivo al compartir de experiencias.
\end{abstract}

Palabras-clave: Educación superior. Desarrollo profesional. Formación docente. Profesor universitario.

\footnotetext{
* Doutora em Educação pela Pontifícia Universidade Católica do Paraná (PUCPR). Mestre em Educação pela PUCPR. Professora na área de Comunicação do Instituto Federal do Paraná (IFPR).<http://orcid.org/0000-0003-4922-8092>. E-mail: <patricia.meyer@ifpr.edu.br>.

** PhD em Engenharia Química, Universidade Federal de Santa Catarina. Professora do Curso de Engenharia de Alimentos da PUCPR. Diretora de Suporte à Graduação na Pontifícia Universidade Católica do Paraná PUCPR. <http://orcid.org/0000-0002-9086-7032>. E-mail: <c.spricigo@pucpr.br>.

*** PhD em Ciências Naturais, Bergische Universität Wuppertal. Professora do Programa de Pós-Graduação em Tecnologia em Saúde da PUCPR. Coordenadora do Centro de Ensino e Aprendizagem da PUCPR - CrEAre. <http://orcid.org/0000-0003-1178-0367>. E-mail: <elisangela.manffra@pucpr.br>.

**** PhD em Educação, Université de Montréal - Canadá. Professor at Pontifical Catholic University of Parana, Programa de Pós-Graduação em Educação. Pesquisadora do Centro de Ensino e Aprendizagem da PUCPR - CrEAre. <http://orcid.org/0000-0002-9508-0888>. E-mail: <dilmeire.vosgerau@pucpr>.
} 
Tão complexo quanto convencer o corpo diretivo de uma instituição de ensino superior (IES) a se comprometer com o desenvolvimento profissional de seus professores é engajar o professorado em uma mudança de cultura. Um desafio que implica articular os interesses pessoais dos docentes e as necessidades institucionais (ZABALZA, 2004), superar o produtivismo acadêmico e a intensificação do trabalho docente (VOSGERAU; ORLANDO; MEYER, 2017), confrontar o desprestígio da docência e a fragilidade do conceito de pedagogia universitária (CUNHA, 2010). A docência em si não se constitui em assunto relevante para a universidade como instituição (ZABALZA, 2009), o que é lamentável diante da evidência de que os saberes relacionados aos conteúdos de ensino não são suficientes para uma boa atuação profissional do professor universitário.

Formado em uma cultura universitária ainda voltada para transmissão e adoção de formas tradicionais de ensino, o docente, comumente, não é preparado para a docência e reproduz em sala de aula as mesmas estratégias de ensino às quais foi submetido (SAROYAN; AMUNDSEN, 2004).

A formação dos professores de ensino superior é uma atribuição das instituições ou uma iniciativa dos próprios docentes, porque a legislação é tímida e negligente em relação ao tema (VOSGERAU; ORLANDO; MEYER, 2017). Mestrados e doutorados formam para a pesquisa, desconsiderando a necessidade de formação específica para a docência. Os professores exercem diferentes atividades no ensino, pesquisa, extensão e gestão, enquanto os processos de seleção ainda são definidos apenas pela titulação e pelo conhecimento específico (ZABALZA, 2004).

Veiga et al. (2012) ressaltam que incluir o conhecimento pedagógico dos professores como pauta nas universidades requer uma firme vontade política. O tema está associado a questões sensíveis em âmbito institucional, tais como recursos financeiros; avaliação do corpo docente; autonomia e solidão profissional; competitividade e intensificação do trabalho, gerando reações negativas, resistências; e recuos, característicos de processos com dimensão institucional e coletiva.

Com base nessa constatação, destaca-se a necessidade de debater a mobilização institucional como um fator de potencialização ou de perda de vigor dos programas de desenvolvimento profissional. A ausência de políticas públicas que tratem da formação dos professores universitários (VOSGERAU; ORLANDO; MEYER, 2017) exige que as instituições de ensino assumam esse compromisso. Aos programas de pós-graduação stricto sensu, segundo a legislação, é atribuída a responsabilidade pela formação profissional do professor de ensino superior, embora a formação pedagógica não faça parte das intenções formais desse nível de ensino nem em programas de educação. Os estágios de docência não são suficientes para suprir essa lacuna (VEIGA et al., 2012).Essa formação precisa ser articulada com o projeto político-pedagógico institucional e com os dos cursos, o que está intimamente relacionado a uma perspectiva coletiva de reflexão sobre o contexto educacional e sobre como o professor constrói sua prática (VEIGA et al., 2012). A mobilização institucional, portanto, incorpora o engajamento da gestão e do professorado. Sendo que um dos desafios é o entendimento de que o programa de formação docente precisa ser permanente e ter sistematização, o que consiste em concepção, planejamento e avaliação, documentação e ajustes no processo (ZABALZA, 2003), ao contrário de ações descontextualizadas ou de iniciativas descontinuadas.

Neste estudo, para o entendimento do caso, considerou-se pertinente a comparação com outras experiências de programas de desenvolvimento profissional. Para tanto, adota-se a compilação de cinco experiências apresentadas por Veiga et al. (2012), fruto de trabalho coletivo de pesquisa interinstitucional desenvolvido na Universidade de Brasília (UnB) e no Centro Universitário de Brasília (UniCEUB) ${ }^{1}$, entre 2009 e 2012. Tem-se por objetivo refletir sobre as possibilidades e limites dos programas de desenvolvimento profissional, numa perspectiva institucional, para o exercício da docência na educação superior. A investigação dos programas demonstra trajetórias marcadas por mudanças na gestão institucional, reações negativas do professorado, limites e até retrocessos, o que permite concluir que existiram políticas de gestão, mas não institucionais.

Esta pesquisa analisa o desafio da mobilização institucional na formação didático-pedagógica de docentes a partir da atuação de setor responsável pela formação de professores (Centro de Ensino e Aprendizagem $\mathrm{CREARE}^{2}$ ) no âmbito de uma universidade com cerca de 22 mil estudantes e 1.500 professores em mais de 50 cursos de graduação. A reflexão sobre esse caso pode contribuir para que outras instituições de ensino superior empreendam políticas institucionais de desenvolvimento profissional docente, superando ações pontuais, além de gerar uma repercussão positiva que implique mudança de cultura. Para tanto, apresenta-se uma descrição

\footnotetext{
1 Diversas obras e artigos sistematizam estratégias institucionais de formação docente nas universidades; entretanto, a seleção dessa compilação ocorreu devido à adoção de um percurso metodológico e de categorias de análises comuns entre as cinco experiências selecionadas.

2 O nome da instituição de ensino superior (PUCPR), assim como o setor responsável pelo programa de formação docente (CREARE) estudado foram omitidos enquanto o artigo esteve sendo submetido à apreciação e avaliação. Há a autorização da instituição para divulgação, assim como parecer favorável do Comitê de Ética de Pesquisa (1.501.381).
} 
sobre o processo de criação de um centro de ensino e aprendizagem (2014-2016) na instituição de ensino superior privada, comunitária e confessional pesquisa$\mathrm{da}$, discutindo as estratégias adotadas em programas de desenvolvimento profissional e comparando-as, especialmente no que tange à mobilização institucional. A descrição contempla o contexto, a origem, a inserção administrativa e as características estruturais do programa de formação docente instituído pelo centro.

\section{Procedimentos metodológicos}

Embora a criação do Centro de Ensino e Aprendizagem tenha se efetivado em 2015, foi em 2014 que se constituiu o cenário que possibilitou a sua fundação e formatação. Entre 2014 e 2016 foram coletados documentos primários (materiais de divulgação, troca de informações por e-mail), produzidos relatórios e notas de campo de reuniões e eventos, com potencialidade de registro da história do centro. As fontes de informação que compõem o estudo estão apresentadas no Quadro 1.

Para compor o estudo, optou-se pela multiplicidade de fontes que permitissem a triangulação dos dados, contribuindo para a validação dos resultados (CRESWELL, 2014). A coleta foi empreendida entre abril de 2014 e novembro de 2016, conforme apresentado na matriz do Quadro 2.

Também foram adotadas como procedimentos de validação a descrição detalhada do objeto estudado e a verificação dos membros do centro, os quais tiveram acesso à descrição e a análises preliminares com intuito de assegurar maior credibilidade e precisão ao relato (CRESWELL, 2014). Os procedimentos adotados visaram à criteriosa elaboração de um estudo de caso qualitativo com intuito de contribuir para a interlocução acerca do desenvolvimento profissional de professores universitários, a partir de uma experiência provocativa no sentido de mudança de cultura institucional.

Quadro 1. Análise documental

\begin{tabular}{|l|l|}
\hline Tipo de documentos & Descrição \\
\hline $\begin{array}{l}\text { Princípios orientadores do processo } \\
\text { de ensino e aprendizagem }\end{array}$ & $\begin{array}{l}\text { Documento resultante de discussões empreendidas no Comitê de Inovação na Graduação (CIG), } \\
\text { em fevereiro de 2014, e coordenado pela Pró-Reitoria de Graduação. }\end{array}$ \\
\hline $\begin{array}{l}\text { Plano de Desenvolvimento de } \\
\text { Graduação (PDG) }\end{array}$ & Documento que define as diretrizes, metas estratégicas para a graduação. \\
\hline Relatório de Autoavaliação 2015 & $\begin{array}{l}\text { Relatório que se constitui documento institucional desenvolvido com engajamento de } \\
\text { todas as unidades acadêmico-administrativas, sob a supervisão da Comissão Própria de } \\
\text { Avaliação (CPA), dos Núcleos de Excelência Pedagógica (NEP) das escolas com } \\
\text { suporte da Assessoria da Reitoria. }\end{array}$ \\
\hline $\begin{array}{l}\text { Matérias que citam o centro no site } \\
\text { institucional (5) }\end{array}$ & $\begin{array}{l}\text { Matérias institucionais selecionadas a partir de pesquisa exploratória no site institucional } \\
\text { com o termo de busca "Creare". }\end{array}$ \\
\hline
\end{tabular}

Fonte: As autoras, 2017.

Quadro 2. Matriz de coleta de dados

\begin{tabular}{|l|l|l|}
\hline Instrumento & Fonte & Descrição \\
\hline Três registros em áudio & $\begin{array}{l}\text { Pró-reitor de graduação } \\
\text { Coordenadora do centro }\end{array}$ & $\begin{array}{l}\text { Encerramento do Fórum dos Núcleos de Excelência Pedagógica (NEP) } \\
\text { em 2014. Abertura e encerramento do Simpósio de Práticas Docentes } \\
\text { em 2016. }\end{array}$ \\
\hline $\begin{array}{l}\text { Uma entrevista } \\
\text { semiestruturada }\end{array}$ & Membro do centro & Entrevista com roteiro e registro em áudio. \\
\hline $\begin{array}{l}\text { pez observações dos } \\
\text { oficinas de formação }\end{array}$ & $\begin{array}{l}\text { Professores e membros } \\
\text { do centro }\end{array}$ & $\begin{array}{l}\text { Fórum dos Núcleos de Excelência Pedagógica (2014). Abertura do } \\
\text { Ciclo de Debates sobre os Princípios da Graduação com os professores } \\
\text { (2014). Seminário de apresentação dos projetos-piloto dos Núcleos de } \\
\text { Excelência Pedagógica (2014). Simpósio de Práticas Docentes (2015). } \\
\text { Oficina Estudo de Caso e Problem Based Learning (Aprendizagem } \\
\text { Baseada em Problemas) (2015). Palestra Alenoush Saroyan, da } \\
\text { University McGill (2015). Simpósio de Práticas Docentes (2016).três } \\
\text { edições do Café CREARE (realizadas nos meses de setembro, outubro e } \\
\text { novembro de 2016). }\end{array}$ \\
\hline
\end{tabular}

Fonte: As autoras, 2017. 


\section{A ORIGeM do Centro de Ensino E APRENDIZAGEM}

Em 2014, a instituição, por meio da Pró-Reitoria de Graduação, ${ }^{3}$ iniciou um intenso processo de reflexão institucional acerca dos processos de ensino e aprendizagem com intenção de aprimorar o processo pedagógico desenvolvido na instituição (PUCPR, 2015a). O processo foi desencadeado por meio da formação de um Comitê de Inovação da Graduação $(\mathrm{CIG}),{ }^{4} \mathrm{com}$ a responsabilidade de produzir um Plano de Desenvolvimento da Graduação (PDG), partindo da definição dos "Princípios Orientadores do Processo de Ensino e Aprendizagem" (PUCPR, 2014). Essa definição amparou-se em uma "perspectiva de mudança cultural que envolve toda a comunidade universitária", com o "objetivo de elevar a qualidade dos cursos de graduação"e "atualizar a universidade para enfrentar e ou corresponder aos desafios da sociedade contemporânea" (MARTINS et al., 2014, p.3). Em âmbito institucional, a mudança cultural teve a finalidade de envolver toda a comunidade acadêmica nas adaptações necessárias para tornar a universidade verdadeiramente um espaço educativo (OLIVEIRA; MARTINS, 2014).

Os princípios definidos para nortear e promover o engajamento da comunidade acadêmica são autonomia, senso crítico, dedicação, cooperação e honestidade (PUCPR, 2014). Já o Plano de Desenvolvimento (PDG), ao apontar as diretrizes, metas e estratégias para a graduação até 2022 , contempla a integração entre a pesquisa, a extensão, a inovação, o desenvolvimento tecnológico e a internacionalização no ensino de graduação. "A opção estratégica da PUCPR é a implantação de um modelo educacional orientado pelos conceitos de formação por competências e educação emancipadora"(PUCPR, 2015a, p. 101). O PDG também impulsionou uma mudança no processo de ensino e aprendizagem, empreendida desde 2014 e voltada para a adoção de metodologias para aprendizagem ativas.

Em fevereiro de 2015, a Pró-Reitoria de Graduação criou o Centro de Ensino e Aprendizagem da PUCPR, vinculado à Diretoria de Suporte à Graduação. O centro foi incialmente composto por sete professores, ${ }^{5}$ sendo um

\footnotetext{
3 A Pró-Reitoria de Graduação foi instituída em 2014, em substituição à Pró-Reitoria Acadêmica, quando uma nova equipe assumiu a Reitoria PUCPR. Sua criação consolida a priorização da graduação (PUCPR, 2016b).

${ }^{4} \mathrm{O}$ comitê foi composto por pró-reitores, diretores da Pró-Reitoria de Graduação, decanos das escolas, diretores das demais unidades da PUCPR, dois representantes da área de Educação e o diretor da Agência PUCPRPUCPR de Inovação - com foco em Ciência, Tecnologia e Inovação; é responsável por articular a universidade com o setor empresarial, potencializando a atuação da instituição na promoção de desenvolvimento socioeconômico (PUCPR, 2015a).

5 Os professores membros do Centro de Ensino e Aprendizagem da PUCPR são de diferentes áreas do conhecimento: um doutor em
}

gestor e outros dois profissionais de suporte administrativo. Os docentes que compõem o centro permanecem com dedicação parcial à sala de aula na graduação e na pósgraduação, o que traz o diferencial de que eles também vivenciam os contratempos apresentados na formação, além de desenvolverem as oficinas dentro da perspectiva institucional. O centro conta também com suporte de consultores externos, pesquisadores de desenvolvimento profissional que atuam em universidades internacionais com assessoramento pedagógico.

A ideia inicial foi,segundo uma das formadoras, inspirada na organização de outras universidades, criar uma solução que pudesse integrar, orientar e sistematizar as diferentes frentes de atuação relacionadas à formação docente em desenvolvimento simultâneo na instituição, atendendo aos direcionamentos do Plano de Desenvolvimento da Graduação (PDG). O CREARE é uma estratégia para mudança institucional, para gerar inovação ${ }^{6}$ no processo de ensino e aprendizagem realizado na universidade. A coordenadora do centro define que ele tem como finalidade "fornecer apoio para o desenvolvimento docente", com intuito de ajudar os professores universitários a se descobrirem como docentes, ${ }^{7}$ em uma perspectiva de que cada um é responsável por esse processo (autonomia). Menciona o entendimento de que o desenvolvimento docente é conquistado todos os dias, na trajetória de cada professor, e que cabe ao CREARE potencializar esse processo já "natural ao professor que quer melhorar suas práticas em sala de aula".

Ao abordar essa trajetória, a coordenadora menciona que há diferentes formas de conduzir esse processo. Há aqueles que partem de modelos e referências adotados por professores presentes em sua vida acadêmica ou profissional, e empreendem diariamente um exercício de lapidação, a partir de tentativas e erros. Para alguns, esse comportamento gera reflexão acerca de sua prática, numa busca por identificar pontos fortes e fracos e potencializar seus resultados. Outros procuram, de forma autônoma, estudar temáticas, métodos e teorias de ensino em iniciativas não promovidas pela instituição. Participam de eventos em educação ou ainda realizam cursos, leituras ou pós-graduações por conta própria. Em comum, essas

Educação (graduação em Informática), um doutor em Física (graduação em Engenharia Industrial Elétrica), um doutor em Engenharia Química (graduação em Engenharia de Alimentos), um doutor em Filosofia, dois mestres em Educação (um com graduação em Pedagogia e outro em Letras) e um mestre em Medicina.

6 Entende-se por inovação, conforme Zabalza (2003), a introdução de processos que possam melhorar a qualidade do que está sendo feito de forma não forçada, justificada, viável e com acompanhamento sistematizado, visando à obtenção de resultados observáveis e tangíveis. Autores como Cunha (2010) e Zabalza (2004 e 2009) apontam que a identidade profissional do docente universitário é construída ao longo de sua trajetória profissional, mas que por vezes é a formação na área de conhecimento de origem que prevalece. 
iniciativas tendem a ser solitárias. Para a coordenadora, é nesse sentido a principal atuação do Centro de Ensino e Aprendizagem, isto é, convencer o professor a abandonar um cenário de solidão em que as trocas são esporádicas e dependentes de iniciativas pessoais. "Vejo o CREARE como um reconhecimento da instituição ao esforço dos docentes para se desenvolverem." Após mencionar as diferentes atividades realizadas, a coordenadora acrescenta: "Em todas as ações, a ideia é oportunizar o aprendizado e permitir que os professores possam auxiliar os colegas a aprender".

Na PUCPR, o movimento em prol da inovação nos processos de ensino na graduação envolve o desenvolvimento de competências, preconizado pelo Projeto Político Pedagógico Institucional, desde 2012, e pela incorporação de metodologias para aprendizagem ativa. ${ }^{8}$ Para concretizar a mudança curricular para a abordagem de competências está prevista a revisão dos Projetos Pedagógicos dos Cursos (PPCs), assim como um processo de formação e assessoria voltado para decanos das escolas, professores atuantes no Núcleo Docente Estruturante (NDE) e coordenadores de curso.

\section{ATUAÇão}

A atuação do Centro de Ensino Aprendizagem da PUCPR (CREARE) é dividida em dois níveis: professor e cursos. No segundo, o público atendido são os coordenadores e os membros do NDE. São oito frentes de atuação, sendo o primeiro nível composto por seis frentes e o segundo, por outras duas, as quais se articulam em diferentes atividades empreendidas pela equipe, conforme a Figura 1. A pesquisa permeia todo o processo, por

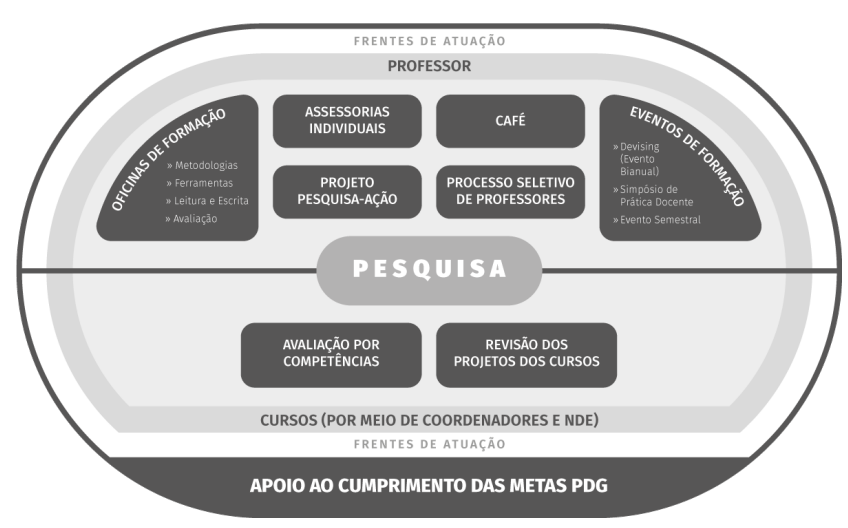

Figura 1. Atuação do Centro de Ensino e Aprendizagem PUCPR

Fonte: As autoras, 2017.

\footnotetext{
8 No âmbito institucional, entendem-se como metodologias para aprendizagem ativa aquelas voltadas para a promoção do protagonismo do estudante em seu processo de aprendizagem e para o seu engajamento em estratégias de pensamento de alto nível.
}

avaliações e validações sistemáticas promovidas de forma integrada em cada atividade, assim como pela articulação com o grupo de pesquisa "Criatividade e Inovação Docente no Ensino Superior (Cides)", ${ }^{9}$ atrelado ao Programa de Pós-Graduação em Educação.

Segundo a coordenadora, as diferentes frentes de atuação, além de sistematizar o desenvolvimento profissional na instituição, têm como propósito contribuir para o aprendizado do professor, estimulando a cooperação entre eles nessa trajetória. O Quadro 3 caracteriza as frentes de atuação do CREARE.

As frentes de atuação (Quadro 3) com foco na socialização atendem à visão de que o desenvolvimento da docência como profissão depende da prática partilhada e do franco diálogo. O trabalho coletivo integra e interioriza condutas, expectativas, valores e posicionamentos. E o desafio de compartilhar dá sentido à prática, sintetizando o conhecimento e podendo gerar pesquisa (TAYLOR; COLET, 2010).

Nesse sentido, a frente de formação docente realizada por meio de oficinas é agrupada em quatro eixos: Ferramentas, Metodologias Ativas, Avaliação da Aprendizagem, Leitura e Escrita, conforme a Figura 2. Enquanto o eixo de Ferramentas pretende orientar os docentes no uso de recursos tecnológicos que podem potencializar estratégias de ensino mais ativas em sala de aula, o eixo de Metodologias Ativas pretende promover a transformação do processo de ensino e aprendizagem. Já o eixo de Avaliação propõe que o professor desenvolva protocolos que permitam que o estudante possa realizar a sua autoavaliação e também a reflexão sobre o seu erro. Por último, o eixo de Leitura e Escrita prevê que o professor possa aprimorar sua leitura e elaboração de textos, levando essas estratégias para sua atuação com os estudantes. As oficinas do Eixo de Ferramentas são ofertadas a partir de parceria com a equipe da Coordenação de Tecnologias Educacionais, a qual também está vinculada à mesma diretoria. $\mathrm{O}$ trabalho entre os setores é de cooperação, na medida em que os professores da PUCPR são instrumentalizados acerca dos recursos tecnológicos pela equipe multidisciplinar de pedagogos e designers instrucionais, porém com forte aderência à proposta pedagógica promovida pelo centro. Até mesmo as ações de planejamento em relação ao eixo são realizadas conjuntamente.

Em 2015, o Centro de Ensino e Aprendizagem também promoveu um eixo de Competências, por meio do qual promoveu oficinas, com base no livro de Gérard Scallon, para membros dos NEP, NDE e coordenadores, visando à formação teórica sobre avaliação da aprendizagem na abordagem por competências (PUCPR, 2015a).

\footnotetext{
${ }^{9}$ O grupo de pesquisa Criatividade e Inovação no Ensino Superior (Cides) é certificado pela PUCPR e credenciado no CNPQ. Outras informações sobre a atuação do grupo podem ser obtidas em $<$ https://sites.google.com/ site/cidesPUCPR>.
} 
Quadro 3. Caracterização das frentes de atuação

\begin{tabular}{|c|c|c|c|}
\hline Frentes de atuação & Público & Foco & Caracterização \\
\hline Oficinas de Formação & Professores & Formação & $\begin{array}{l}\text { Classificadas em eixos (Figura 2). Têm cargas horárias diferenciadas e } \\
\text { calendário divulgado semestralmente. A inscrição é voluntária. }\end{array}$ \\
\hline Assessorias Individuais & Professores & Formação & $\begin{array}{l}\text { Agendadas conforme a necessidade do professor que participou das } \\
\text { oficinas e tem dificuldades. }\end{array}$ \\
\hline Café CREARE & Professores & Socialização & $\begin{array}{l}\text { Realizado mensalmente, é um espaço de compartilhamento de } \\
\text { experiências de ensino, visando à criação de uma comunidade de } \\
\text { prática. Há um tema para cada edição. Após a apresentação das } \\
\text { experiências por voluntários, há um debate, e um lanche fica à } \\
\text { disposição. As inscrições são limitadas ( } 50 \text { docentes e três estudantes de } \\
\text { licenciatura). Nas três primeiras edições, participaram } 97 \text { docentes. }\end{array}$ \\
\hline Processo seletivo & Professores & Formação & $\begin{array}{l}\text { Desde 2016, após realizar a reformulação das rubricas de avaliação } \\
\text { para a prova didática no processo de seleção, os membros do CREARE } \\
\text { participam das bancas como avaliadores. O uso de metodologias para } \\
\text { aprendizagem ativa alinhado ao desenvolvimento de resultados de } \\
\text { aprendizagem foi incluído como critério. }\end{array}$ \\
\hline Eventos de formação & Professores & $\begin{array}{l}\text { Formação e } \\
\text { Socialização }\end{array}$ & $\begin{array}{l}\text { Três tipos de eventos são organizados: } \\
\text { (a) O Devising, a cada dois anos, traz profissionais de renome nacional } \\
\text { e internacional da área de educação. A participação é limitada, mas } \\
\text { o valor do congresso é subsidiado para professores da instituição } \\
\text { (PUCPR, 2016c). } \\
\text { (b) Os Simpósios de Prática Docente, anuais, com propósito de } \\
\text { compartilhar, divulgar, discutir experiências e promover a reflexão } \\
\text { sobre as ações pedagógicas (PUCPR, 2015c). Os professores podem } \\
\text { se inscrever, voluntariamente, como painelistas - apresentando suas } \\
\text { experiências, ou apenas como ouvintes. Na primeira edição (2015) } \\
\text { participaram } 125 \text { docentes e foram apresentadas } 39 \text { experiências; na } \\
\text { seguinte, } 109 \text { professores e } 43 \text { experiências. } \\
\text { (c) É a acolhida dos professores a cada semestre. Discute temas } \\
\text { fundamentais para o desenvolvimento institucional e outros eventos } \\
\text { pontuais (PUCPR, 2015b). }\end{array}$ \\
\hline $\begin{array}{l}\text { Projeto de Inovação } \\
\text { na Graduação }\end{array}$ & Professores & $\begin{array}{l}\text { Pesquisa-ação } \\
\text { educacional* }\end{array}$ & $\begin{array}{l}\text { Projeto de desenvolvimento de experimentos pilotos em inovação } \\
\text { metodológica e formação de multiplicadores em aprendizagem ativa. } \\
\text { Prevê artigos a partir das experiências. }\end{array}$ \\
\hline $\begin{array}{l}\text { Abordagem de } \\
\text { aprendizado por } \\
\text { competências }\end{array}$ & $\begin{array}{l}\text { Coordenadores } \\
\text { e NDE }\end{array}$ & $\begin{array}{l}\text { Articulação } \\
\text { institucional** }\end{array}$ & Formação e assessoria envolvendo decanato e NDE. \\
\hline $\begin{array}{l}\text { Revisão dos projetos } \\
\text { dos cursos }\end{array}$ & $\begin{array}{l}\text { Coordenadores } \\
\text { e NDE }\end{array}$ & $\begin{array}{l}\text { Articulação } \\
\text { institucional }\end{array}$ & $\begin{array}{l}\text { Suporte ao NDE para reformulação dos Projetos Pedagógicos de Cursos } \\
\text { (PPCs) na perspectiva de abordagem de aprendizado por competências. }\end{array}$ \\
\hline
\end{tabular}

* Entende-se por pesquisa-ação educacional um tipo de investigação-ação com o objetivo de aprimorar a prática ao intercalar, de forma organizada, o agir e o investigar. É uma "estratégia para o desenvolvimento de professores e pesquisadores de modo que eles possam utilizar suas pesquisas para aprimorar seu ensino e, em decorrência, o aprendizado de seus alunos" (TRIPP, 2005, p.445).

** Identificou-se como "Articulação Institucional" as ações do Centro de Ensino e Aprendizagem voltadas para reforçar a concepção pedagógica e de educação institucional, que permeia as diferentes frentes de atuação, nos documentos institucionais norteadores das diretrizes de cada curso e, consequentemente, de cada escola, integrando a gestão e a atuação realizadas efetivamente em sala de aula pelos docentes.

Fonte: As autoras, 2017.

A Figura 2 também demonstra que o planejamento do CREARE contempla a revisão das propostas das oficinas ao longo dos semestres, incluindo e suprimindo ofertas ou agrupando temáticas. Em entrevista com um dos membros do centro, identifica-se que o contato frequente entre os docentes e a equipe, além das avaliações, permite o monitoramento dos interesses e a readequação a partir dos problemas apresentados. Sendo assim, há um cuidado com a sistematização de todo o processo empreendido. A organização da oferta das oficinas é flexível, a partir de um planejamento semestral, com base no acompanhamento da participação dos professores e de suas sugestões. As oficinas são orientadas pela proposição da metodologia da aprendizagem ativa, promovendo isomorfismo 


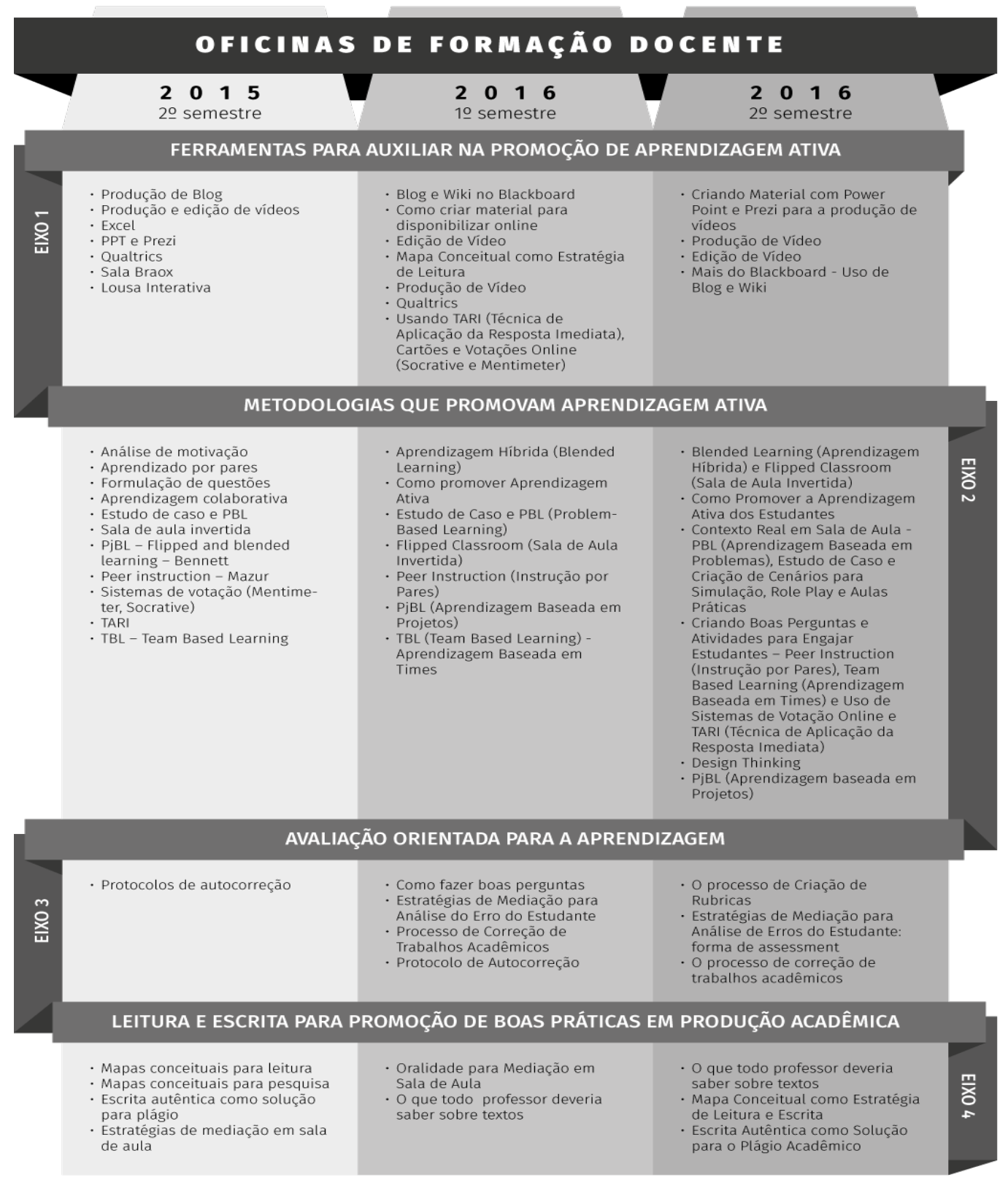

Figura 2. Oficinas de Formação Docente

Fonte: as autoras.

pedagógico, ${ }^{10}$ e pelos princípios da graduação. Temáticas como "atuação em equipes" e "responsabilidade em dar e receber feedback" são discutidas de forma integrada aos princípios (PUCPR, 2015d) e à ementa da oficina. Há incentivo ao estudo prévio individualizado com suporte de ambiente virtual de aprendizagem (AVA) e à integração de docentes de diferentes áreas (socialização).

Aberta para os professores de todas as escolas e cursos, a oferta das oficinas apresenta-se apenas com

\footnotetext{
${ }^{10}$ Entende-se por isomorfismo pedagógico (NIZA, 2009) fazer com que os docentes experienciem nas oficinas os procedimentos e os métodos, o envolvimento e as posturas, os recursos e as práticas sugeridos pela temática do evento.
}

limitações no número de participantes devido ao espaço físico e também visando à melhor qualidade no atendimento aos docentes. A divulgação é realizada em toda a instituição, por meio de cartazes, site institucional, boletim eletrônico e blog específico para prestar informações sobre o calendário das atividades de formação, tanto as oficinas como o Simpósio de Práticas Docentes e o Café. Um livro sobre os princípios também serve como suporte à formação docente e à mobilização institucional. Lançado durante o Devising, o livro relata a experiência de professores e gestores com cada um dos cinco princípios orientadores do ensino de graduação (PUCPR, 2016d). 
Há uma estratificação em relação ao nível de participação dos professores nas Oficinas de Formação Docente, contemplada no planejamento do setor, que confere certificados com cargas horárias diferenciadas (Quadro 4).

Quadro 4. Oficinas de Formação Docente: níveis de participação

\begin{tabular}{|l|l|}
\hline $\begin{array}{l}\text { Diferentes níveis de participação } \\
\text { dos docentes }\end{array}$ & Certificação \\
\hline $\begin{array}{l}\text { Após a inscrição on-line, comparecem } \\
\text { à oficina e participam em sua totalidade } \\
\text { (parte presencial e disponível no AVA). }\end{array}$ & $\begin{array}{l}\text { Horas/aulas } \\
\text { cursadas }\end{array}$ \\
\hline $\begin{array}{l}\text { Depois da participação, comprometem-se a } \\
\text { realizar a aplicação da metodologia estudada, } \\
\text { promovendo para isso um replanejamento } \\
\text { de sua disciplina e uma nova configuração } \\
\text { para seu plano de ensino. Contam com } \\
\text { assessoria individual. }\end{array}$ & $\begin{array}{l}\text { Horas/aula } \\
\text { cursadas }\end{array}$ \\
\hline $\begin{array}{l}\text { Professores que participam da oficina } \\
\text { aplicam as metodologias aprendidas em } \\
\text { suas disciplinas e, como uma última etapa, } \\
\text { redigem um relato reflexivo acerca da } \\
\text { experiência. }\end{array}$ & $\begin{array}{l}\text { Declaração } \\
\text { de 30h }\end{array}$ \\
\hline
\end{tabular}

Fonte: As autoras.

Notadamente, não é a certificação em si que incentiva os docentes a finalizarem o ciclo, mas o fortalecimento de sua dimensão profissional, além da articulação entre a formação didático-pedagógica e de reflexão sobre a própria prática, buscando sua ressignificação em uma perspectiva inovadora. Isso se dá, principalmente, porque há um intenso diálogo entre os professores e os membros do centro, por meio de encontros presenciais e atendimentos por e-mail, que permitem que o docente se sinta incentivado a transformar sua prática.

O número total de professores que participaram de todas as atividades do centro (em 2015 e 2016), sem a contabilização do evento Devising e da frente de atuação relacionada à abordagem por competências, é de 764, o que corresponde a $54 \%$ da comunidade docente da PUCPR.

Os próximos passos do centro contemplam um maior investimento em oficinas voltadas para a avaliação de aprendizagem, demanda apresentada pelos docentes. Outros direcionamentos para 2017 são a formação em planejamento de disciplina, visando a incorporar um novo modelo de plano de ensino coerente com os objetivos e resultados de aprendizagem construídos por meio da abordagem por competências, da ampliação das assessorias individuais e das oficinas ofertadas. $\mathrm{O}$ que contempla diferentes níveis de experiências dos professores com a aprendizagem ativa.

\section{O DESAFIO DA MOBILIZAÇÃO INSTITUCIONAL}

A universidade objetiva, segundo o Plano de Desenvolvimento da Graduação (PUCPR, 2016b), elevar a qualidade do ensino nos cursos de graduação. Para tanto, é necessário, segundo o pró-reitor de graduação, a mudança de cultura e de crenças, para que "as pessoas acreditem que é melhor mudar". É essencial realizar o processo "com capilaridade, permitindo essa transformação". Para essa nova cultura institucional, que possibilite que o estudante universitário experimente "novos conhecimentos, novas relações afetivas, novas metodologias, novos modelos de gestão, novas formas de compreender e de organizar o mundo" (PUCPR, 2016a, p.33), é preciso "mudar o modelo mental das pessoas".

Cada uma das frentes de atuação do centro e as atividades destas derivadas têm o objetivo de, conforme o pró-reitor, "promover uma mudança cultural que quer fazer da PUCPR um centro de aplicação e difusão de novas metodologias de ensino, visando à formação de cidadãos e de profissionais qualificados para enfrentar os desafios do mundo contemporâneo" (PUCPR, 2015b). Uma das formas de se promover essa mudança é a articulação de diferentes ações, o que justifica as frentes de atuação, sua inserção na estrutura administrativa da instituição e os esforços articulados de comunicação institucional. Outra forma de alavancar a mudança cultural é alterando processos de gestão, valorizando a adesão dos professores por meio da avaliação institucional e do avanço na carreira. "É essencial o modelo prever a valorização das iniciativas inovadoras no que tange às metodologias ativas, critério que precisa estar atrelado à progressão na carreira docente" (PUCPR, 2016b).

Ao avaliar o trabalho do centro, o pró-reitor enfatizou que um dos focos de resistência se origina no intenso trabalho e dedicação que requer a reorganização do ensino e aprendizagem, tanto na formação quanto no replanejamento da prática, nas estratégias de avaliação e reflexão ao longo de todo o processo, até a naturalização. O gestor ressaltou que a mudança cultural na IES perpassa três pontos: reafirmar um compromisso no desenvolvimento de competências nos estudantes - o que diverge de uma perspectiva conteudista; tornar o estudante ativo em sua aprendizagem; e deixar claro que as metodologias, técnicas e estratégias visam a facilitar os pontos anteriores, mas não são objetivos em si. O intuito dessa afirmação é estimular a inovação por meio da formação, assim como a heterogeneidade e a profissionalização docente, pois não se trata de uma iniciativa de padronização; os professores não são apenas executores de diretrizes, podem ser criativos e contar com o centro para superar as dificuldades. Os objetivos do Centro 
de Ensino e Aprendizagem estão associados à mudança da concepção da graduação, documentada por meio dos Princípios Orientadores, do Plano de Desenvolvimento da Graduação, e articulada com a revisão dos projetos político-pedagógicos dos cursos. Também estão sendo empreendidas mudanças na avaliação institucional, com intuito de valorizar profissionalmente os professores engajados no processo de inovação.

\section{DISCUSSÃO A PARTIR DA RELAÇÃo COM OUTROS PROGRAMAS DE DESENVOLVIMENTO CONTINUADO}

As experiências relatadas por Veiga et al. (2012), em programas de desenvolvimento profissional (Quadro 5) da Universidade Federal de Pernambuco (UFPE), da Universidade Vale do Itajaí (UNIVALE), da Universidade de Chapecó (Unochapecó), da Universidade de Caxias do Sul (UCS) e da Universidade de São Paulo (USP), foram categorizadas em: premissa, cenário, objetivos, inserção administrativa na organização, características da estrutura organizacional do programa, práticas formativas desenvolvidas, importância atribuída ao programa e limites.

O programa que apresentou mais características semelhantes com a experiência da PUCPR é o de Aperfeiçoamento de Ensino (PAE) da USP. É possível citar: o suporte de uma assessoria externa; as diferentes frentes de atuação do programa; a forte presença de experiências de socialização entre os docentes; a articulação com a Pró-Reitoria de Graduação;a perspectiva de revisão da

Quadro 5. Comparação entre estratégias institucionais para desenvolvimento profissional docente em universidades

\begin{tabular}{|c|c|c|c|c|c|c|}
\hline & PUCPR & UFPE & Univale & Unochapecó & UCS & USP \\
\hline Premissa & $\begin{array}{l}\text { Potencializar o } \\
\text { desenvolvimento } \\
\text { profissional docente } \\
\text { pelo incentivo à } \\
\text { sociabilização e } \\
\text { mudar a cultura } \\
\text { acadêmica. }\end{array}$ & $\begin{array}{l}\text { Redimensionar o } \\
\text { papel do docente } \\
\text { como transmissor e } \\
\text { autoridade. }\end{array}$ & $\begin{array}{l}\text { Promover o ensino } \\
\text { de conhecimentos } \\
\text { específicos e } \\
\text { condições próprias } \\
\text { para exercício da } \\
\text { profissão. }\end{array}$ & $\begin{array}{l}\text { Investir na } \\
\text { profissionalização } \\
\text { docente, incentivando } \\
\text { a revisão de práticas } \\
\text { conservadoras no } \\
\text { ensinar. }\end{array}$ & $\begin{array}{l}\text { Envolver o professor } \\
\text { na pesquisa e } \\
\text { reflexão de suas } \\
\text { práticas pedagógicas, } \\
\text { rompendo com o } \\
\text { autodidatismo. }\end{array}$ & $\begin{array}{l}\text { Substituir os } \\
\text { enfoques didáticos } \\
\text { centrados na prática } \\
\text { docente e no ensino } \\
\text { para atividades } \\
\text { exercidas pelos } \\
\text { estudantes. }\end{array}$ \\
\hline $\begin{array}{l}\text { Práticas } \\
\text { formativas }\end{array}$ & Quadro 3 & $\begin{array}{l}\text { Curso presencial } \\
\text { e atividades de } \\
\text { campo (observação } \\
\text { da prática) com } \\
\text { 45h. Participação } \\
\text { de professores de } \\
\text { diversas a áreas. } \\
\text { Socialização } \\
\text { e atendimento } \\
\text { individual. }\end{array}$ & $\begin{array}{l}\text { Cursos, oficinas, } \\
\text { palestras, mesas- } \\
\text { redondas, relatos } \\
\text { de experiências, } \\
\text { videoconferências } \\
\text { e atividades EAD. } \\
\text { Programa de } \\
\text { 100h dividido em } \\
\text { eixos. Atividades } \\
\text { de pesquisa-ação } \\
\text { (experiências } \\
\text { pedagógicas). } \\
\text { Produção de } \\
\text { Cadernos de Ensino. }\end{array}$ & $\begin{array}{l}\text { Cursos, oficinas } \\
\text { práticas, ciclos } \\
\text { de estudos } \\
\text { obrigatórios, cursos } \\
\text { de pós-graduação em } \\
\text { docência universitária } \\
\text { para formação } \\
\text { de articuladores } \\
\text { pedagógicos, criação } \\
\text { de revista científica. }\end{array}$ & $\begin{array}{l}\text { Acompanhamento } \\
\text { por meio de reuniões } \\
\text { com professores } \\
\text { iniciantes, assessoria } \\
\text { individual, diferentes } \\
\text { seminários como } \\
\text { de formação para } \\
\text { docência, para uso } \\
\text { de tecnologias e em } \\
\text { EAD etc. Minicursos } \\
\text { de processos } \\
\text { cognitivos. }\end{array}$ & $\begin{array}{l}\text { Curso de Pedagogia } \\
\text { Universitária (240h) } \\
\text { configurado como } \\
\text { especialização, } \\
\text { socialização das } \\
\text { experiências. } \\
\text { Seminários } \\
\text { de Pedagogia } \\
\text { Universitária ao vivo } \\
\text { e transmitidos via } \\
\text { videoconferência, } \\
\text { produção de cadernos } \\
\text { de textos. }\end{array}$ \\
\hline Limites & $\begin{array}{l}\text { Carência de recursos } \\
\text { humanos no centro, } \\
\text { enfrentamento } \\
\text { de resistências e } \\
\text { descrenças de parcela } \\
\text { do professorado, } \\
\text { que considera um } \\
\text { "modismo". }\end{array}$ & $\begin{array}{l}\text { Espaço físico e } \\
\text { recursos humanos } \\
\text { insuficientes } \\
\text { (sobrecarga de } \\
\text { trabalho para } \\
\text { aqueles que atuam } \\
\text { no programa e } \\
\text { acumulam funções). } \\
\text { Necessidade } \\
\text { de melhoria na } \\
\text { divulgação dos } \\
\text { eventos para maior } \\
\text { engajamento e } \\
\text { mobilização. } \\
\text { Dificuldade dos } \\
\text { professores de } \\
\text { disporem de horários } \\
\text { para participar das } \\
\text { oficinas. }\end{array}$ & $\begin{array}{l}\text { Programa requer } \\
\text { atualização } \\
\text { frequente a partir } \\
\text { de novas demandas } \\
\text { e exigências de } \\
\text { formação. }\end{array}$ & $\begin{array}{l}\text { Enfrentamento } \\
\text { de resistência } \\
\text { de professores } \\
\text { que apontavam a } \\
\text { "pedagogização" } \\
\text { da universidade. } \\
\text { Tentativa frustrada } \\
\text { de participação } \\
\text { voluntária na formação } \\
\text { após período de } \\
\text { obrigatoriedade. } \\
\text { Descontinuidade } \\
\text { no programa. } \\
\text { Solidão profissional, } \\
\text { produtivismo } \\
\text { acadêmico e } \\
\text { competitividade, } \\
\text { também considerados } \\
\text { limitadores ao } \\
\text { envolvimento docente. } \\
\text { Falta de sistematização } \\
\text { (acompanhamento) } \\
\text { das ações. }\end{array}$ & $\begin{array}{l}\text { Necessidade de } \\
\text { expandir para } \\
\text { outras unidades } \\
\text { (capilaridade). }\end{array}$ & $\begin{array}{l}\text { Urgência na } \\
\text { priorização } \\
\text { orçamentária e } \\
\text { organizacional } \\
\text { para que não exista } \\
\text { descontinuidade } \\
\text { do programa. } \\
\text { Necessidade de } \\
\text { diminuir a sobrecarga } \\
\text { de trabalho gerada } \\
\text { pela substituição de } \\
\text { assessoria externa } \\
\text { por professores } \\
\text { da Faculdade } \\
\text { de Educação... } \\
\text { Priorização de } \\
\text { fontes e estratégias } \\
\text { diversificadas. }\end{array}$ \\
\hline
\end{tabular}

Fonte: As autoras, a partir de Veiga et al. (2012), 2017. 
avaliação institucional com intuito de que as prerrogativas de premissas de formação gerassem valorização profissional;a tentativa de ampliar as ações pontuais e tornar a formação articulada com a realidade em sala de aula e com os problemas acadêmicos, superando a intuição e o empirismo para conscientizar acerca da própria prática. A articulação das estratégias demonstra a superação de uma perspectiva técnica e instrumental na formação. As experiências da Univale e da Ufpe também têm similaridades com a PUCPR no que tange às premissas e ao incentivo à socialização ao investir na formação didático-pedagógica, privilegiando espaços de interação entre docentes de um mesmo curso ou de áreas diversas e superando as especificidades e o individualismo. Outra preocupação da Univale, em comum com a iniciativa da PUCPR, é a atualização frequente do programa.

Os programas da Unochapecó e da UCS apresentam semelhanças mais pontuais. Na UCS, é possível destacar, por exemplo, a articulação com a avaliação institucional (também comum à USP), a intenção de romper com o empirismo, ou seja, com uma prática de tentativa e erro não sistematizada e com foco apenas na experiência, bem como as diferentes frentes formativas de atuação, porém com a presença da assessoria individual. Na Unochapecó, as similaridades estão no incentivo para que o professor reveja sua prática, rendendo-se à inovação por meio de novos conhecimentos teóricos. A mobilização institucional é tema em destaque na descrição da experiência da USP porque houve a criação de uma estrutura organizacional específica para coordenar as ações de formação docente, com profissionais especializados, assessores externos e funcionários, assim como destinação de orçamento para promoção das diferentes frentes de trabalho. Houve priorização da formação docente no cenário institucional e uma tentativa de buscar estabilidade, evitando a descontinuidade do programa - tentativa frustrada em 2010. A temática também é abordada pelo viés da duração na iniciativa da Univali. Experiência que já foi analisada em distintos artigos científicos, o que reforça a necessidade de avaliação e atualização constantes no programa de formação docente. A Unochapecó foi a única das experiências relatadas que implementou a obrigatoriedade da participação docente, embora essa imposição fosse contraditória com as premissas do programa e a alteração na coordenação também tenha gerado descontinuidade no programa.

Com o intuito de potencializar a mobilização e o engajamento dos docentes, duas iniciativas (Ufpee USP) apontam ser necessário um planejamento cuidadoso da divulgação das ações de formação docente. A comunicação institucional precisa ser uma aliada do processo, utilizando diversos, porém articulados, veículos para a difusão das informações. Somadas, as experiências apontam como limites: a sobrecarga e a intensificação do trabalho docente, que implica a dificuldade de dispor de horários para as atividades; a resistência a um discurso de "pedagogização" da universidade; e a competitividade.

Mesmo uma iniciativa articulada de mobilização institucional, que visou a gerar engajamento, desde o princípio, enfrenta desafios relacionados à desconfiança e à descrença. No caso analisado, são apontados como fatores desencadeantes: a burocratização, associada às avaliações e à necessidade de sistematização e de acompanhamento das mudanças instituídas; a composição multidisciplinar da equipe do centro e o fato de não estar atrelada diretamente a um departamento ou programa de pós-graduação em Educação; e a visão da iniciativa institucional como um modismo, um atentado à autonomia do professor, como se ele fosse apenas um mero executor de decisões institucionais ou que estas apenas resultassem em sobrecarga de trabalho. O discurso desmobilizador é reforçado por críticas relativas à empregabilidade e à manutenção do emprego - no sentido de que aqueles que não atendem às diretrizes têm reduzidas as chances de ascensão profissional, bem como as condições de trabalho, especialmente no que se refere à ausência de horas complementares.

Um diferencial da proposição da PUCPR é a construção de pressupostos que norteiem toda iniciativa de inovação na graduação, com participação do professorado. A criação e discussão dos princípios da graduação e a reflexão sobre sua influência no comportamento de professores e estudantes construiu uma tessitura para a mobilização. Cabe ressaltar, também, no âmbito da própria organização, a definição de contrapartidas em relação ao intenso esforço que significa mudar, como redesenhar a avaliação institucional e criar ações de valorização. Dar estabilidade ao processo (VEIGA et al., 2012) é fundamental; do contrário, a comunidade não se sentirá encorajada diante do risco de tentativa e erro. A estabilidade também está relacionada ao planejamento, à avaliação e à sistematização, ou seja, à existência de documentos institucionais (ZABALZA, 2003) respaldando e criando um ambiente favorável, além de estar vinculada ao desafio de efetivar a estratégia como institucional e não como pertencente a uma gestão, para não gerar descontinuidade dos processos. Evidenciar o comprometimento da instituição com a inovação, por meio de ações concretas, como eventos e pronunciamentos públicos, e promover estratégias de divulgação de todo o processo (transparência) também é essencial.

Não obstante, visando a superar a descrença, o planejamento dos programas precisa contemplar ações voltadas a minimizar os obstáculos à participação docente, criando estratégias não apenas para que o professor esteja informado, seja sensibilizado e persuadido, mas também 
para que seja seduzido pela iniciativa. Componentes fundamentais nesse sentido são a constituição de frentes de atuação que tornem o processo presente em diversos contextos institucionais, $\mathrm{o}$ atendimento a interesses individuais e coletivos a partir das temáticas e conteúdos, assim como a proposição de atividades diversificadas, tanto presenciais como não presenciais, com variedade de metodologias.

É vital identificar o professor como parte principal, motor de uma vivência universitária plena e marcante, e reconhecer a diversidade de identidades e perfis dos docentes e áreas de atuação, assim como a maneira de construir e de se relacionar com o conhecimento. A universidade foi entendida, então, como um "espaço de exercício das diferenças", como uma "comunidade de discordância" (MARTINS et al., 2014, p. 15). Por isso, na PUCPR, o processo partiu da compreensão de que as mudanças não poderiam ser verticalizadas, mas deveriam ter organicidade.

Zabalza (2009) afirma que não há melhoria no ensino universitário sem esforços em prol da formação docente, da constituição da identidade profissional e de competências para seu exercício. Nesse sentido, o processo de constituição do centro também é interessante, na medida em que lança a proposição de formação docente alicerçada e como motor de uma mudança institucional. Alinhado às perspectivas de Zabalza (2009, p. 75), assim como de Bedard, Clement e Taylor (2010), o trabalho do centro incita que o professor seja um especialista em seu campo específico e um estrategista no desenvolvimento da aprendizagem ativa do estudante. Ao reconhecer a docência como uma profissão especializada, que não pode ser baseada, portanto, apenas na prática ou na experiência, o projeto tem por objetivo promover formação e reflexão sobre a própria prática, de forma articulada aos interesses institucionais (TAYLOR; COLET, 2010). Evidencia-se que a proposição, em sua constituição, assemelha-se ao que Zabalza (2009, p. 77) define como "facilitar a aprendizagem". As diferentes frentes de atuação do CREARE dedicam-se a demonstrar que ensinar não é apenas explicar, é "fazer aprender", o que implica que os docentes devem dominar distintas estratégias que possibilitem instigar o estudante a realizar o acompanhamento de seu processo, bem como os ajudar a alcançar os objetivos de aprendizagem.

\section{CONSIDERAÇÕES FINAIS}

É inevitável buscar na formação a resposta para a necessária renovação na cultura profissional dos professores universitários. Contudo, um eficiente programa de formação capaz de valorizar a docência, incentivar a profissionalização e permitir que os professores exerçam de forma consciente e competente sua prática requer engajamento, tanto individual como institucional. A formação não pode ser meramente uma política de gestão, um projeto sem sistematização ou descontextualizado das demandas profissionais dos docentes. Exige formação dos formadores, planejamento, tanto das frentes de atuação e atividades quanto de ações paralelas para dar voz, visibilidade e permissão para superação da cultura acadêmica do individualismo promovendo a sociabilização. $\mathrm{O}$ engajamento também não implica apenas levar o docente a participar de ações de formação ou refletir autonomamente acerca de sua prática, mas também torná-lo multiplicador. Aqueles que mais se envolvem em atividades de formação são os que não apenas sentem a necessidade de continuar se aprofundando, mas se transformam em patrocinadores das formações.

\section{REFERÊNCIAS}

BEDARD, D.; CLEMENT, M.; TAYLOR, K. L. Validation of a conceptual framework. In: SAROYAN, A.; FRENAY, M. (Ed.). Building teaching capacities in higher education:a comprehensive internacional model. Sterling, Virginia: Stylus, 2010. p. 168-187.

CUNHA, M. I. da. Trajetórias e lugares de formação universitária: da perspectiva individual ao espaço institucional. Araraquara: Junqueira\&Marin, 2010.

CRESWELL, J. W. Investigação qualitativa e projeto de pesquisa: escolhendo entre cinco abordagens. 3. ed. Porto Alegre: Penso, 2014.

MARTINS, V. et al. O comitê de inovação na graduação e a elaboração de princípios para a graduação como uma estratégia de mudança na cultura universitária: a experiência da PUCPR. In: COLÓQUIO INTERNACIONAL DE GESTÃO UNIVERSITÁRIA, 14., 2014, Florianópolis.

NIZA, S. Contextos cooperativos e aprendizagem profissional: a formação no movimento da Escola Moderna. In: FORMOSINHO, João (Org.). Formação de professores: aprendizagem profissional e ação docente. Porto: Porto Editora, 2009. p. 345-362.

OLIVEIRA, J. R.; MARTINS, V. Visão estratégica da graduação: a experiência da PUCPR. In: COLÓQUIO INTERNACIONAL DE GESTÃO UNIVERSITÁRIA, 14., 2014, Florianópolis.

PUCPR. Princípios Orientadores do Processo de Ensino e Aprendizagem. Curitiba, 2014.

PUCPR. Relatório de Autoavaliação. Curitiba, 2015a. Disponível em: www.pucpr.br/arquivosUpload/1237081891429272795. pdf. Acesso em: 20 out.2016.

PUCPR. PUCPR promove oficinas e conferências sobre metodologias ativas com Eric Mazur e Bennet Goldberg Curitiba, 20 jul. 2015. 2015b. Disponível em: <http://www. pucpr.br/escolademedicina/csnoticia.php?ref=1\&id=201507-20_58239>. Acesso em: 22 nov. 2016. 
PUCPR. Evento busca compartilhar experiências e refletir sobre as práticas docentes na graduação. Curitiba, 10 set. 2015. 2015c. Disponível em: <http://www.pucpr.br/noticia. php?ref=1\&id=2015-09-10_59058>. Acesso em: 22 nov. 2016.

PUCPR. Evento acontece de 21 de setembro a 12 de dezembro e oferta aos professores diversas oficinas. Curitiba, 18 set. 2015. 2015d. Disponível em: <http://www.pucpr.br/noticia. php?ref=1\&id=2015-09-18_59221>. Acesso em: 22 nov. 2016.

PUCPR. Formação docente. Curitiba, 2016a. Disponível em: $<$ http://www.formacaodocentepucpr.com.br/>. Acesso em: 21 nov. 2016.

PUCPR. Plano de desenvolvimento da graduação. Curitiba: PUCPRess, 2016b. Disponível em: <https://livraria.pucpr.br/ pdg/pdf/PDG_PLANO_DESENVOLVIMENTO.pdf $>$. Acesso em: 16 nov. 2016 .

PUCPR. Sobre devising. Curitiba, 22 jun. 2016. 2016c. Disponível em: <http://www.pucpr.br/noticia.php?ref=1\&id= 2016-06-22_62445>. Acesso em: 16 nov. 2016.

PUCPR. Livro de professores da PUCPR discute princípios orientadores para o ensino superior. Curitiba, 25 jul. 2016. 2016d. Disponível em: <http://www.pucpr.br/escolademedicina/ csnoticia.php?ref=1\&id=2016-07-25_62896>. Acesso em: 16 nov. 2016.

SAROYAN, A.; AMUNDSEN, C. Rethinking teaching in higher education: from a course design workshop to a faculty development framework. Sterling: Stylus Publishing, 2004.

TAYLOR, K. L.; COLET, N. R. Making the shift from faculty development to educational development. In: SAROYAN, A.; FRENAY, M. (Ed.). Building teaching capacities in higher education: a comprehensive internacional model. Sterling, Virginia: Stylus, 2010. p. 139-167.

TRIPP, D. Pesquisa-ação: uma introdução metodológica. Educ. Pesq., São Paulo, v. 31, n. 3, p. 443-466, dez. 2005.

VEIGA, I. P. A. et al. Universidade e desenvolvimento profissional docente: propostas em debate. Araraquara, SP: Junqueira \& Marin, 2012.

VOSGERAU, D. S. R.; ORLANDO, E. A.; MEYER, P. Produtivismo acadêmico e suas repercussões no desenvolvimento profissional de professores universitários. Educ. Soc., Campinas, v. 38, n. 138, p. 231-247, jan. 2017.

ZABALZA, M. A. Innovación en la enseñanza universitaria. Contextos educativos. Revista de Educación, [S.1.], p. 113-136, maio 2003. Disponível em: <https://publicaciones.unirioja.es/ ojs/index.php/contextos/article/view/531>. Acesso em: 20 abr. 2017.

ZABALZA, M. A. O ensino universitário: seu cenário, seus protagonistas. Porto Alegre: Artmed, 2004.

ZABALZA, M. A. Ser professor universitário hoy. La cuestión universitária, Madrid, n. 5, p. 69-81, 2009. Disponível em $<$ http://polired.upm.es/index.php/lacuestionuniversitaria/ article/view/3338>. Acesso em: 7 dez. 2016.

Recebido em 31.05.2017

Aprovado em 27.03.2017

Endereço para correspondência:

Patrícia Meyer

Travessa Ângelo Piazzetta, 30 apto 21 - Cristo Rei

80050-460 Curitiba, PR, Brasil 